\title{
Discovery Driven Innovation: The Case of Oman Entrepreneurship
}

\author{
Dr. Maria Teresa Matriano \\ Assistant Professor, Department of Management Studies \\ Middle East College, Muscat, Oman
}

\begin{abstract}
Businesses around the world fail or succeed because decisions good or bad were made out of assumptions of the unknown. In the context of discovery-driven innovation, business decision can be made with the aid of available information based from passed attempts, the current market situation, and consumer dynamics. The discussion involves examining the importance of discovery-driven innovation in business growth. Oman ha young SME sector in which several entrepreneurs succeed and failed due to a common cause, which is the lack of drive to discover what works for their business and the lack of innovation applied to their operational strategies. Discovery-driven innovation in the case of Oman encompasses the limitations faced by entrepreneurs in reinventing their business ideas based from data about the past and existing enterprises. In discovering what works, what did not work, and why it didn't, entrepreneurs would be able to make evidence-based decision that can assist them in innovating the way they do business.
\end{abstract}

Keywords: Commercialization, Consumer Market, New Products, Business Process/strategies

\section{INTRODUCTION}

Every now and then stories are told about businesses that gained global success from a single idea that when turned into an innovation has changed the world over. One notable example that can be taken into account is the success of Facebook that from the time of its launch has redefined the concept of social media. In context, discovery-driven innovations can be attributed to the discovery of new ideas that materialized through the aid of technology. When talking about innovation, it doesn't necessarily translate into an object of technology, but rather an evolution of an idea that was modified to meet the market demands. The characteristics of a discovery-driven innovation can be observed among smart companies that incur considerable losses when entering new markets, new alliances, and new technologies (McGrath and MacMillian, 1995). Companies such as Federal Express incurred $\$ 600$ million in losses when they ventured into a fax product

called Zap-mail. Another notable example is Walt Disney that incurred an astounding \$1 Billion in losses after venturing into the European market (McGrath and MacMillian, 1995). On the other hand, one can learn from experience and the losses does not always imply a negative outcome because the failures from such ventures allowed the companies to redefine their idea of innovation to create something that is worth all the efforts, resources, and time.

When incurring failure that discovery is being made, and the information obtained from the experience can be a valuable tool to plan for the future. This is when the context of discoverydriven innovation comes to play. In the case of Oman, the concept of discovery-driven innovation can be attributed to entrepreneurs who are venturing into the known with the objective of establishing their name in the SME sector. In this discussion, the concept of discovery-driven innovation will be explored through the lenses of the current Omani entrepreneurial ecosystem. It is known that Oman is an oil-based economy, with a small 
private sector that makes up the alternative sector of the Oman economy. What makes the concept of discovery-driven innovation very much applied to Oman's SME situation is the fact the sector is still in the premature stage. In this sense that failure and risks are at a higher probability, but beyond that is a sea of opportunities that entrepreneurs can take for their advantage and establish an entrepreneurial environment that is driven by discoveries of new innovations. Furthermore, the discussion will also highlight the concept of discovery-driven innovation from theoretical perspectives presented in various literatures.

\section{DISCOVERY-DRIVEN INNOVATION CONCEPT}

The term discovery-driven is often associated with business planning that pertains to the strategies that takes into account the implications of unpredictable environment (McGrath, 2010). Business models adapted around the world has evolved dramatically with the integration of new technologies enabling a faster, cost-effective, and convenient way of communicating and transferring information. More importantly, the concept of discoverydriven innovation is very easy to understand, which means that the only plan is to learn as you go (Global Focus, 2009). Not all companies has made perfect decisions throughout their business cycles. Even large global companies hits the wall when past decision were found unfavorable in the new environment despite the amount of research and planning made before making the decision. However, discovery-driven is all about learning and taking that experience as the basis for innovation. According to the article published by Abbott (n.d.), discovery-driven innovation is about fresh thinking about the products/services that were built based on the foundations of consumer insights. This means that success is not always drawn from introducing new products/services to the market, but by thinking the way consumers think and be able to translate that into a product/service that consumers actually needs.

Discovery-driven innovation can be also attributed to individuals who possess the five important characteristics of an innovator according to Woods (2016). The first skill is associating, which is a cognitive capability of an innovator to put themselves in different disciplines and excel in all of them. By means of excelling in various fields is taking leadership in presenting new ideas to improve the current standards. The second characteristic of innovators is questioning, which is a way to engage prevailing ideas with questions of "what if?" and "what is?" (Midgley, 2010). For instance a manager would ask the staff, "who is your target customer?', "what kind of experience do they need?", "what do they want?", and "what our product is missing today?" (Midgley, 2010). Answering these questions are imperative in discovering what the market wants from the organization and find ways to fill the gap of things that are lacking. Entrepreneurs as innovators, it is important to ask similar questions in the objective of discovering the best possible scenarios that could make or break the business. In the case of Oman as a young SME country, there are a lot of questions that entrepreneurs in the country would need to ask its market in order to plan strategies that would imply innovations that are discover-driven.

\section{DISCOVERY-DRIVEN INNOVATION IN OMAN}

Strong winds of economic change is sweeping the country recently because of the threats to the economy of the prevailing oil price volatility. The implications of relying largely on one industry to build Oman's economy is a sort of discovery that the government can use to remodel its economic structures and innovate through diversification. The government of Oman has learned that the lack of economic flexibility in their case would result to stagnant growth and lack of opportunities for the other economic sectors to flourish. This is the reason that recent innovations are beginning to emerge into the spotlight in Oman as a response to the need for creating a more diversified economy. Attempts were made in Muscat to introduce new 
international export developments, but the uncertainty and the struggle to innovate is preventing the planned development to take flight (Bryant, 2017). In addition, the focus of capacity building in Oman is to find new ventures that would introduce the economy to a different means of growth. From the context of discovery-driven innovation, it is important that past and current information are used in the process of discovering new economic paths. This is one of the reason that innovators in the country are looking at the traditional industries to build new innovative solutions. One of the best examples here is the development of marine biotechnology, which was an idea that emerged from the fact that Oman is once reliant on its fishing industry prior to the oil discovery (Al-Belushi et al., 2015).

The country has a long coastline and vast marine ecosystem that when utilized as resource for innovation can create an economic opportunity. National innovation performance is important for Oman in its current economic state particularly when considering discovery as innovation driver (Al-Belushi et al., 2015). Another important discovery-driven innovation in Oman can be associated to its oil industry. The fact of discovery for Oman is that the oil industry is vulnerable to the global price movement. With that information in mind, it is ideal that a new form of economic alternative has to be developed to combat the implications of oil price volatility to the economy. This is when the idea of developing the SME sector came to light. However, even the development of the SME sector is also faced with challenges and failures due to the lack of foundation that will support the growth of every entrepreneurs. Part of the solution to the problem is to innovate the way support is provided to entrepreneurs through a mentorship network wherein the private sector participates in sharing valuable insights about the various markets to the SMEs (Entrepreneur Staff, 2016). The mentorship network can be considered as a discovery-driven innovation because it was founded from the result of multiple failures of the SMEs in Oman to establish growth.

\section{CHALLENGES ASSOCIATED WITH DISCOVERY-DRIVEN INNOVATION}

New Ideas are easy to create and new businesses doesn't run out of it, but the real challenge is the process of materializing an idea into something that of great value. The reality for new businesses particularly in Oman is quite difficult in the sense that fewer than half of the startups are still in existence and would still operate in the next five years (al Shaibany, 2017). In general, only $50 \%$ of new ventures are able to survive for more than five years according to the study by Shane (2008). The reason for the high closure rate of new business can be attributed to the discovery-driven initiatives or the lack thereof. When creating a new business around a product especially for new entrepreneurs, there is a lot that they are don't know yet about the unknown. The phase of discovery does not happen prior to operating the business and most often innovation is driven after the discovery learned from the previous failed attempt. Some organizations are willing to invest large amount of capital and resources for an unproven assumption without considering to check the possibilities of the assumptions as being correct. Part of the uncertainties that organizations may face particularly entrepreneurs in the SME may include market imperfection, unreliable infrastructure, absence of government support, uncertainty in price and cost, application of untested technology, and among many others that creates unpredictable competitive response (McGrath, 2010).

The key in discovery-driven innovation is knowing the data to use to ease uncertainty, but in order to tackle the underlying uncertainties, the innovator must also find a way to discover the factors causing the uncertainties. The challenge that discovery-driven innovation entails emerge when there is no prior data available to use as the basis for forecasting. For example, the risk involve in engaging to a new venture is not knowing who the customers are, what they will be, and what they would want. Testing assumptions would be helpful in eliminating the uncertainties of venturing to a new business. This is because failing to evaluate the viability of 
a venture would likely to result to futile activities with higher probability of failure (McGrath and MacMillan, 1995). In the case of Oman, a dramatic drop in the number of SMEs in the country by $31.2 \%$ year on year(SyndiGate.info, 2017) encompasses the lack of initiative to learn from their discovery, and use the information from the prior experiences in innovating strategies to succeed. With the remaining 23,221 SMEs in Oman, the cause of their longevity is to constantly reinvent their ideas to align with the changing needs of the consumer market. One of the issues pointed out as the cause of the decline in the number of SMEs in Oman, is the lack of steady foundation and knowledge base that new entrepreneurs can use to evaluate their venture. In other word, discovery-driven innovation is generally lacking in the country as there are limitations on the available resources that are instrumental in forecasting and anticipating the unknown uncertainties.

\section{DISCUSSION}

The complex challenge faced by SMEs in Oman can be attributed to a number of reasons and one of them is the lack of discovery-driven innovation. According to the SMEF Chief Shaikh Salah Hilal al Maawali, Oman's SME sector is in a complex environment that requires specific solutions that will not come from the educational institutions, private sector, the government, and NGOs; instead, solutions should require collaboration between the aforementioned (Prabhu, 2017). Given that entrepreneurs in the country faces uncertainties, there is an apparent assumption that business will thrive regardless of the situation as long as the money keeps coming. However, the most dangerous assumptions in business are the ones that are unrecognized, which results to the assumptions being untested or unchallenged. In the case of Oman, the uncertainties of whether the market and the consumers would embrace the idea for the new business is often untested. For example, a company has decided to innovate their communication products and also decided to have the sales force specialized in noncommunication device sell the former. The result could not be anything but a failure for two main reasons, one, the existing sales force does not have the knowledge of discovery about the new innovation, and secondly the new innovation has not been tested to match the consumer preferences.

To better get a good grasp of the situation in which discovery-driven innovation is much needed, Oman SME sector faced tremendous challenges because of one common fact, and that is because SMEs are by nature weak, vulnerable, and cannot handle setbacks. In addition, the sector is not able to retain or attract good managers, and most often the entrepreneurs themselves are not good managers (TimesofOman, 2014). Now, given that situation of SMEs in the country, there is one missing ingredient in all of them, which is the capability to learn from the setbacks, and use that discovery to innovate their businesses. There were untested assumptions prior to venturing and the vast majority of the SMEs are not innovative at best given that they sell standard products or services to a niche market (TimesofOman, 2014). This as well encompasses the lack of discovery made by entrepreneurs in Oman to allow their businesses to innovate. Furthermore, the investment efforts made to innovate through technological means is also limited. Similar situations also occurred to some of the biggest companies in the world where decisions were made out of untested assumptions.

It was mentioned in the earlier part of the discussion that companies such as Walt Disney and Federal Express incurred losses because of untested invested decisions. This is very much associated to discovery-driven innovation in terms of planning. For instance, Walt Disney decided to open a theme park in Paris in 1992, which for so many years incurred losses after losses due to lack of foresight to the European market. The company assumed the European market will pay the same ticket price as the American market; second, assumptions were made that visitors would be willing to stay for an average of four days in one of the five hotels in the 
resort; assumptions were made that visitors would buy a mix of high priced merchandise. These assumptions without being challenged by discovery has resulted to losses in 18 out of the 25 years of the theme park's operations. Given the example from the Walt Disney's investment outcome, companies and most especially SMEs not only in Oman, but anywhere else should realize the importance of discovery in making important business decisions. In the case of Oman, discovery in terms of innovation and planning is instrumental in keeping the business afloat. It was mentioned earlier that SMEs in Oman fail because there is no innovation efforts coming from the entrepreneurs. These events of failed ventures can be used as a learning point for emerging entrepreneurs to integrate learning in discovering the best strategies for business growth.

\section{CONCLUSION}

The terms discovery-driven innovation can be treated as a way to reinvent an idea by taking into consideration the factors that made other businesses succeed or failed. In the case of Oman, the number of failing SMEs encompasses as lack of discovery efforts made to reinvent their business strategies. Innovation does not always have to be an application of new technology to aid the business, but rather a re-imagination of ideas that will help the business to grow. In addition, discovery-driven innovation takes into account the assumptions about the market, the consumers, the information from prior strategic attempts, and the technologies that are suitable for application. There is still room for growth for SMEs in Oman, but innovation is one area in which the entrepreneurs would need to discover in order to ease uncertainties and eliminate untested assumptions.

\section{References}

Abbott (n.d.). Discovery Driven Innovation - Abbott Research. [online] Abbott Research. Available at: https://abbottresearch.com/discovery-driven-innovation/ [Accessed 21 May 2018].

alShaibany, S. (2017). Oman to tackle joblessness among young with SME campaign. [online] The National. Available at: https://www.thenational.ae/business/oman-to-tackle-joblessness-among-young-with-smecampaign-1.69374 [Accessed 21 May 2018].

Al-Belushi, K., Stead, S. and Burgess, J. (2015). The development of marine biotechnology in Oman: Potential for capacity building through open innovation. Marine Policy, 57, pp.147-157.

Bryant, P. (2017). Innovation in Oman. [online] Business Today Oman. Available at: http://businesstoday.co.om/Issues/Optimism-in-the-air/Innovation-in-Oman [Accessed 21 May 2018].

Entrepreneur Staff (2016). Building An Ecosystem: Riyada Specialist Mentor Chris Broad On Oman's SME Sector. [online] Entrepreneur. Available at: https://www.entrepreneur.com/article/272755 [Accessed 21 May 2018].

Global Focus (2009). Discovery-driven Growth: The Only Plan Is to Learn as You Go - Knowledge@Wharton. [online] Knowledge@Wharton. Available at: http://knowledge.wharton.upenn.edu/article/discovery-driven-growth-theonly-plan-is-to-learn-as-you-go/ [Accessed 21 May 2018].

McGrath, R. (2010). Business Models: A Discovery Driven Approach. Long Range Planning, 43(2-3), pp.247-261.

McGrath, R. (2010). Fascinating application of discovery driven planning to social ventures - Rita Gunther McGrath. [online] Rita Gunther McGrath. Available at: https://www.ritamcgrath.com/2010/08/fascinating-application-ofdiscovery-driven-planning-to-social-ventures/ [Accessed 21 May 2018].

McGrath, R. and MacMillan, I. (1995). Discovery-Driven Planning. [online] Harvard Business Review. Available at: https://hbr.org/1995/07/discovery-driven-planning [Accessed 21 May 2018].

Midgley, D. (2010). The innovation manual. Chichester: Wiley.

Prabhu, C. (2017). Collaboration key to securing success of Omani SMEs, says SMEF chief-Oman Observer. [online] Oman Observer. Available at: http://www.omanobserver.om/collaboration-key-securing-success-omani-smessays-smef-chief/ [Accessed 21 May 2018].

Shane, S. (2009). Failure Is a Constant in Entrepreneurship. [online] You're the Boss Blog. Available at: http://boss.blogs.nytimes.com/2009/07/15/failure-is-a-constant-in-entrepreneurship/?_r=0 [Accessed 21 May 2018]. 
SyndiGate.info (2017). Dramatic Drop in Number of SMEs in Oman in 2017: Report. [online] Al Bawaba. Available at: https://www.albawaba.com/business/dramatic-drop-number-smes-oman-2017-report-969548 [Accessed 21 May 2018].

TimesofOman (2014). Omani small and medium enterprises facing tremendous challenges: CEO National Company for Projects and Management. [online] Times of Oman. Available at: http://timesofoman.com/article/30430 [Accessed 21 May 2018].

Woods, T. (2016). The 5 Skills of The Innovator. [Blog] hypeinnovation.com. Available at: https://blog.hypeinnovation.com/the-5-skills-of-the-innovator [Accessed 21 May 2018]. 